\title{
Numerical simulation of the influence of the selected factors on the performance of a concrete road barrier H2/W5/B
}

\author{
Lukasz Pachocki ${ }^{*}$, and Krzysztof Wilde ${ }^{1}$ \\ ${ }^{1}$ Gdańsk University of Technology, Faculty of Civil and Environmental Engineering, \\ Department of Mechanics of Materials and Structures, 11/12 Narutowicza Str., 80-233, Gdańsk, \\ Poland
}

\begin{abstract}
This paper discuss the influence of selected factors on the performance of a concrete road barrier H2/W5/B. Modelling techniques of a concrete road safety system were briefly discussed. Comparison to the full scale crash test results has been shown. The concrete road safety barrier has been investigated for evaluation of the overall damage after collision under various initial conditions. The failure assessment criterion has been proposed and it was derived from a qualitative comparison of the numerical results with the full scale crash test data. Impact severity indexes have been calculated and discussed.
\end{abstract}

\section{Introduction}

Each type of a road-safety barrier has to be subjected to the full scale crash test in order to assess the appropriate level of containment and correct values of impact severity indexes [1]. One of the materials used for road safety systems is reinforced concrete. Concrete barriers are used to prevent the vehicle from penetrating the system and to redirect it back to the track with relatively small working width [1]. In Poland, concrete barriers can be often found near bridge columns as shown in fig. 1. While, it is troublesome to predict every possible crash scenario by full scale experimental tests, the numerical methods seem to be very convenient way to do so. Numerical simulations may be a powerful tool as a source of supplementary data for full scale crash tests. In order to acquire reliable numerical results some normative requirements for numerical simulations should be preserved [2]. One of the most popular systems is LS-DYNA explicit dynamic finite element code $[3,4]$. It is widely used tool for crash tests simulations for various types of road restraining systems [5-12] or other special events [13-16]. Thus, numerical methods allow engineers to apply the virtual testing environment in broad spectrum of applications aimed at improving the road safety. According to European Standards [1] in some cases numerical simulations can be used for barrier certification. However, this is possible only if the numerical model was subjected to the validation process [2] and the change in the system is classified as moderate [1]. It this paper the validated model of the concrete barrier is used. Therefore, parametric analysis with various types of vehicles and initial conditions is performed. Results of the numerical simulations allow the engineers to estimate the impact of accident on the participants and on the damage done to road restrained systems. Although, the

\footnotetext{
* Corresponding author: lukpacho@pg.edu.pl
} 
numerical results are considered as reliable, no one should arbitrarily assume the correctness of the numerical solutions and much care must be taken while drawing conclusions from the numerical data.

The paper is organized as follows: section 2 covers the general objectives of the paper and defines the main goals that have been established. Description of the applied methods is given in section 3. Overview of the numerical simulations results of different crash tests is presented in section 4 . Section 5 ends the paper with some concluding remarks.

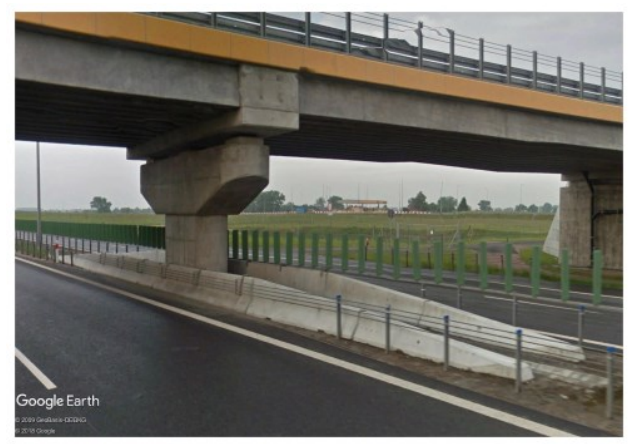

Fig. 1. Bridge column protected by concrete road safety system, credits: Google Earth.

\section{Objectives}

The main goal is to build a reliable numerical model of a concrete road safety barrier that can be used in order to simulate various types of crash events. The proposed series of tests concerns the influence of the vehicle type and initial conditions on the overall damage done to the barrier as well as the severity of the impact. The capabilities and limitations of LSDYNA system were investigated during the process of model creation. In order to simplify the initial conditions to one value it has been assumed to present it as initial kinetic energy of an impact perpendicular to the system. Other goal was to determine set of numerical results for a database that summarize the data for various types of initial conditions of collisions with their influences on the accident participants and the road safety barrier.

\section{Numerical modelling}

The first task is the description of the system geometry for the 3D model for LS-DYNA environment. In concrete barriers interaction between adjacent segments plays crucial role so the boundaries of segments must be precisely modeled. Moreover, location of the steel reinforcement bars must be also accounted for. Next step (fig. 2) is to mesh the elements of the barrier segment. The body of the segment is described by tetrahedral solid elements with the LS-DYNA's element formulation type 10. Connectors of the segment were modelled with hexahedral solid elements with constant stress element formulation. HughesLiu beam element formulation $[3,4]$ was used to model the behavior of steel reinforcement bars. Interaction between concrete and reinforcement was modelled using the constrained formulation. The beam element nodes were constrained to the adjacent tetrahedral solid element nodes using *CONSTRAINED_LAGRANGE_IN_SOLID keyword. An advantage of this approach is that the beam nodes doesn't have to coincide with corresponding solid element mesh of the barrier segment. One global contact has been used *CONTACT_AUTOMATIC_SINGLE_SURFACE. Groups of different contacting materials were specified within *DEFINE_FRICTION keyword so they could have 
different friction coefficients assigned. Friction is assumed as dependent on a relative velocity of the bodies according to the equation

$$
\mu=F D+(F S-F D) e^{-D C\left|V_{r e l}\right|}
$$

where $F D$ means dynamic coefficient of friction, $F S$ is static coefficient of friction, $D C$ describes exponential decay coefficient and is multiplied by $V_{r e l}$ which is the relative velocity of contacting surfaces. Parameters for a friction modelling were obtained from internet resources as well as from U.S. Department of Transportation reports [17,18]. Compliance with the recommendations contained in the standards [2] has also been followed. In order to avoid unwanted element modes excitation Flangan-Belytschko stiffness form of hourglass control was used $[4,19]$. Other major factor of the analysis of the concrete was the selection of the appropriate material law for the concrete. Based on the literature $[20,21]$, one can come to the conclusion that there are couple of reliable material laws that can provide correct results.

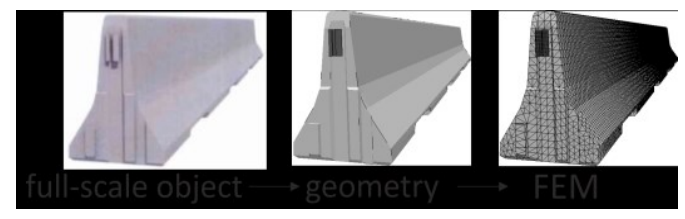

Fig. 2. Simplified scheme for the finite element mesh derivation.

It was decided to use the so-called continuous surface cap model denoted in LS-DYNA as *MAT159_CSCM material law. In [21] calibration methods for that model have been widely described. The decision was based on wide range of reports that proved its reliability $[17,18,22,23]$. In addition theoretical background of the material law is also presented in many papers [3,4,22-25]. The concrete material data, used in model definition, is based on laboratory tests performed on samples from the segment of the barrier.

Steel elements were modelled using piecewise linear plasticity material law with element failure. Simplified strain-stress curve implemented for steel was based on the results from the laboratory tests. Numerical model of the tested concrete road safety barrier consisted of 6 segments each $8 \mathrm{~m}$ long such us the one tested in full scale crash tests. It's length was $48 \mathrm{~m}$ which is the minimal length of the temporary concrete road safety barrier. General view of the analyzed system is presented in fig. 4 with illustration of the initial conditions: angle is described by $\alpha$ whereas velocity is described by $V_{\text {init }}$ vector. Besides, it should be noted that numerical model, described in this paper, passed the validation process positively. Appropriate requirements for the numerical simulations [2] have been fulfilled. Furthermore, extra verification have been performed using MPC and ANOVA metrics [26,27] as suggested in American recommendations for validation [28]. General views of the results obtained in full scale crash test versus results from numerical simulations are displayed in fig. 5. Since good similarity was obtained, further parametric analysis of the unchanged concrete road safety system numerical model was performed. Initial conditions of the vehicle e.g.: impact angle and initial velocity, were assumed as a variable parameters for the analysis. Another varying factor was the vehicle type. Five types of vehicles were used in this research and are shown in fig. 3 : Geo Metro $(900 \mathrm{~kg})$, BMW (1500kg), HGV (10000 kg), bus (13000kg) and HGV (38000 kg). Geo Metro's numerical model was obtained from the NCAC public repository that is currently unavailable. However, Norwegian Public Road Administration still provides it with no charge [29]. BMW's LS-DYNA code was developed by Transpolis (formerly LIER), the 
French crash-test house and digital simulation office for road safety equipment. HGV's models were acquired from the public online resources and subjected to modifications. The coach model, used in simulations, was developed by the Norwegian Public Road Administration (www.vegvesen.no) and is also available free of charge.

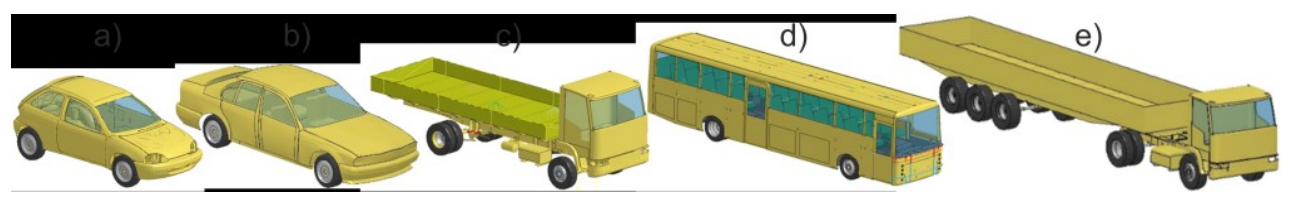

Fig. 3. Vehicles used in the research a) Geo Metro b) BMW c) HGV 10t d) Bus 13t e) HGV 38t.

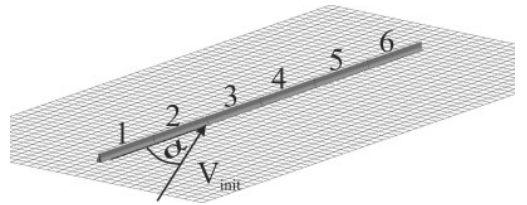

Fig. 4. General view of the analysis setup.

For certain types of vehicles [1] impact severity indexes have been calculated and summarized. The studies focused on determining the damage done to the barrier so the number of damaged barrier segments could be established. It is proposed that effective plastic strain isosurfaces can be failure assessment criterion. Good visual correlation between the full scale object cracks and corresponding numerical model effective plastic strain results have been observed. Visualization representing the described comparison can be seen in fig. 6. Therefore, it was assumed that this criterion may be a good way to establish the number of segments that must be replaced.

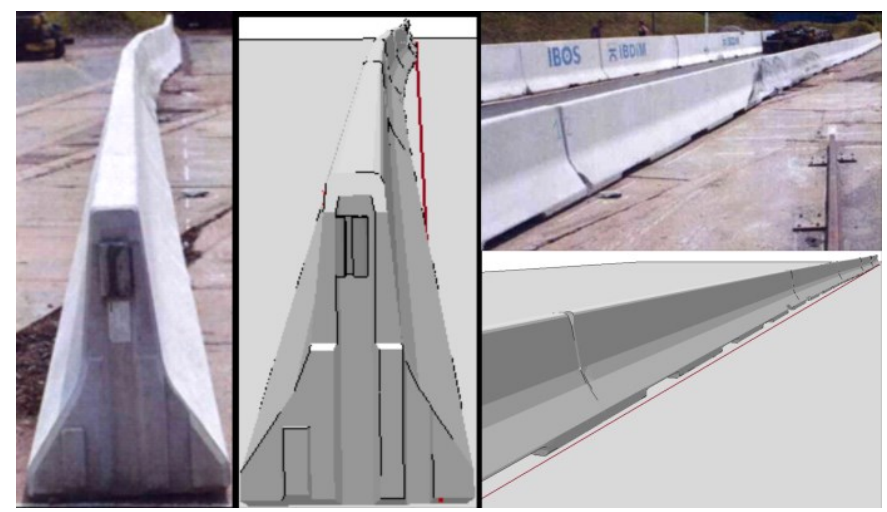

Fig. 5. Comparison of the results from full scale crash test and numerical simulation.

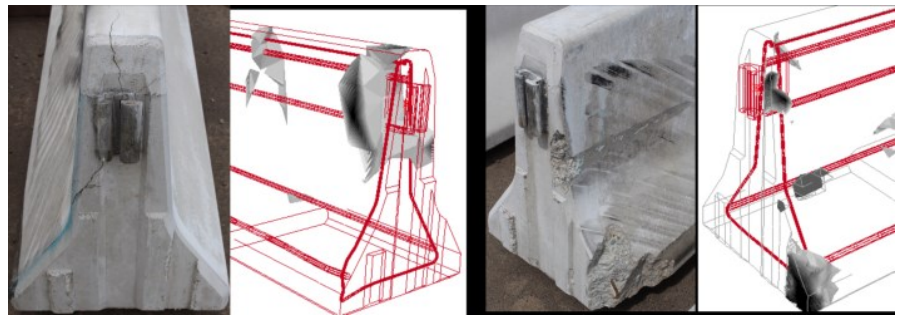

Fig. 6. Effective plastic strain isosurfaces as a proposed failure assessment criterion. 


\section{Results}

Five different vehicle types with different initial impact conditions were taken into consideration. The segments of the barrier have been examined for the breakage according to the effective plastic strain failure criterion described earlier in section 0 . Initial kinetic energy have been calculated for every type of the test's initial conditions. Working widths have been determined according to the European Standards [1] for full scale crash tests. Impact severity indexes for Geo Metro and BMW vehicle were calculated from the appropriate accelerations and velocity of the vehicle's center of gravity. Although it is not required to calculate severity indexes for the heavy vehicles [1] during full scale crash test TB41 such data have also been collected. Hence, it was decided to calculate impact severity indexes for 10 ton heavy goods vehicle. The accelerometer have been mounted to the dashboard. All the simulations had the same impact point set to the about $20 \mathrm{~cm}$ before the connection of the segments 2 and 3, as can be seen in fig. 4 . The first discussed test is the TB11 [1] crash test. The vehicle started the motion with the specified initial conditions and hit the barrier at the impact point. Then, it was redirected in the opposite direction. The overall progress of the car motion can be seen in fig. 7. Characteristic behavior for light vehicles was observed as the vehicle rises. Two barrier segments were assumed broken and their effective plastic strain isosurface is shown in fig. 8. The ASI index determined during the simulation equals to $1.4[-]$ and it classifies the barrier to the B class. Such a result was obtained due to modifications done to the vehicle during the previous study [29]. Next performed numerical simulation is TB32 [1] crash test. The value of the obtained ASI parameter is 1.4 [-]. As the initial kinetic energy raised the number of the damaged segments increased to 3 . The progress of the TB32 collision is portrayed in fig. 9 and the isosurface of the effective plastic strain is shown in fig. 10. Cases, being discussed above, were shown due to their higher severity on the vehicle's occupants. However, the concrete barrier has containment level of $\mathrm{H} 2$, therefore remaining simulations concerns heavy vehicles. The numerical results are summarized in table 1. fig. 11 depicts the influence of the initial kinetic energy (perpendicular to the barrier's face) of HGV 10t and BUS 13t vehicles on the working width until complete breakage of the system.

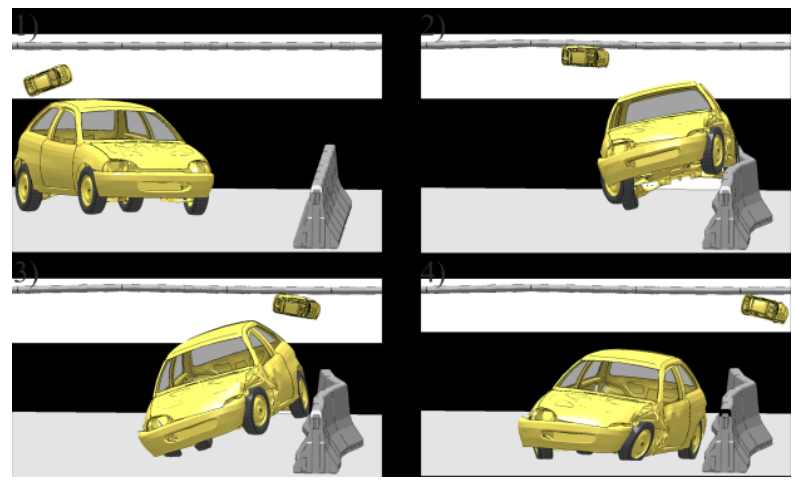

Fig. 7. Progress of the TB11 crash test against concrete barrier.

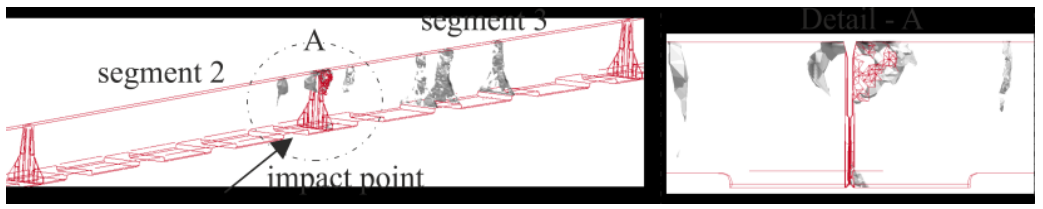

Fig. 8. Effective plastic strain isosurfaces of the concrete road safety barrier segments after collision. 


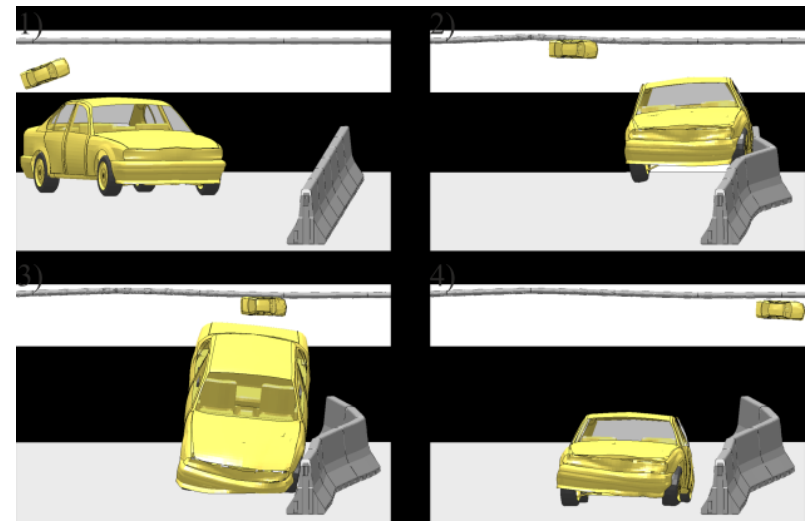

Fig. 9. Progress of the TB32 crash test against concrete barrier.

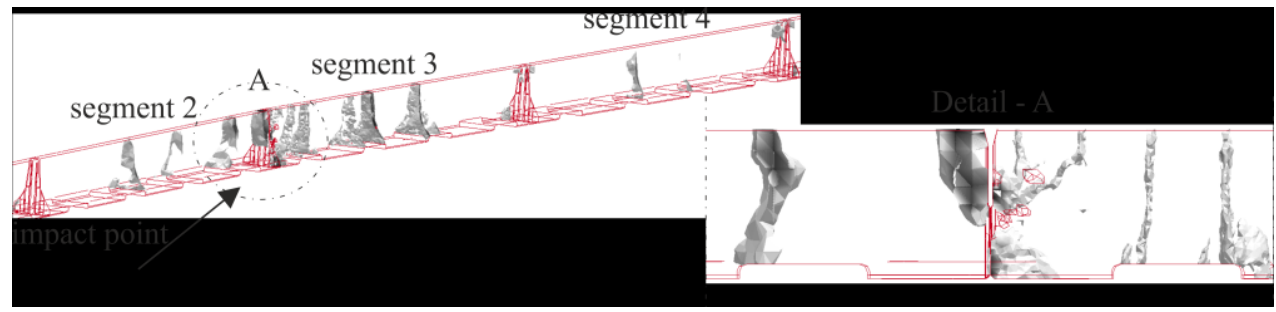

Fig. 10. Effective plastic strain isosurfaces of the concrete road safety barrier segments after collision.

Table 1. Summarization of the tests that have been carried out.

\begin{tabular}{|c|c|c|c|c|c|c|c|}
\hline & $\begin{array}{c}\text { Angle } \\
0\end{array}$ & $\begin{array}{l}\text { Velocity } \\
\text { km/h }\end{array}$ & $\begin{array}{c}\text { Kinetic } \\
\text { Energy kJ }\end{array}$ & $\begin{array}{c}\text { ASI } \\
-\end{array}$ & $\begin{array}{l}\text { THIV } \\
\mathbf{k m} / \mathbf{h}\end{array}$ & $\begin{array}{l}\text { Working } \\
\text { width } \mathrm{m}\end{array}$ & $\begin{array}{c}\text { Broken barrier } \\
\text { segments - }\end{array}$ \\
\hline $\begin{array}{c}\text { Geo Metro } \\
0.9 \mathrm{t}\end{array}$ & 20 & 100 & 41 & 1.4 & 9 & 0.8 (W2) & 2 \\
\hline BMW $1.5 \mathrm{t}$ & 20 & 110 & 82 & 1.4 & 7 & 1.0 (W3) & 3 \\
\hline \multirow[t]{9}{*}{ HGV $10 \mathrm{t}$} & 7 & 70 & 28 & 0.4 & 13 & $0.8(\mathrm{~W} 2)$ & 2 \\
\hline & 8 & 70 & 37 & 0.4 & 13 & 0.9 (W3) & 3 \\
\hline & 8 & 80 & 48 & 0.5 & 13 & 1.1 (W4) & 3 \\
\hline & 8 & 100 & 75 & 0.6 & 14 & 1.9 (W6) & 6 \\
\hline & 20 & 70 & 221 & 0.8 & 15 & 3.0 (W8) & 6 \\
\hline & 20 & 80 & 289 & 0.9 & 20 & $5.1(\mathrm{n} / \mathrm{a})$ & 6 \\
\hline & 20 & 100 & 451 & 2.3 & 21 & $8.4(\mathrm{n} / \mathrm{a})$ & 6 \\
\hline & 45 & 70 & 945 & 1 & 33 & $\mathrm{n} / \mathrm{a}$ & 5 \\
\hline & 90 & 70 & 1890 & 1 & 19 & $\mathrm{n} / \mathrm{a}$ & 6 \\
\hline \multirow[t]{6}{*}{ BUS $13 t$} & 7 & 70 & 37 & - & - & 0.7 (W2) & 2 \\
\hline & 20 & 70 & 287 & - & - & 2.8 (W8) & 5 \\
\hline & 20 & 80 & 375 & - & - & $4.3(\mathrm{n} / \mathrm{a})$ & 5 \\
\hline & 20 & 100 & 587 & - & - & $\mathrm{n} / \mathrm{a}$ & 5 \\
\hline & 45 & 70 & 1229 & - & - & $\mathrm{n} / \mathrm{a}$ & 5 \\
\hline & 90 & 70 & 2458 & - & - & $\mathrm{n} / \mathrm{a}$ & 6 \\
\hline HGV 38 t & 20 & 65 & 725 & - & - & $\mathrm{n} / \mathrm{a}$ & 6 \\
\hline
\end{tabular}




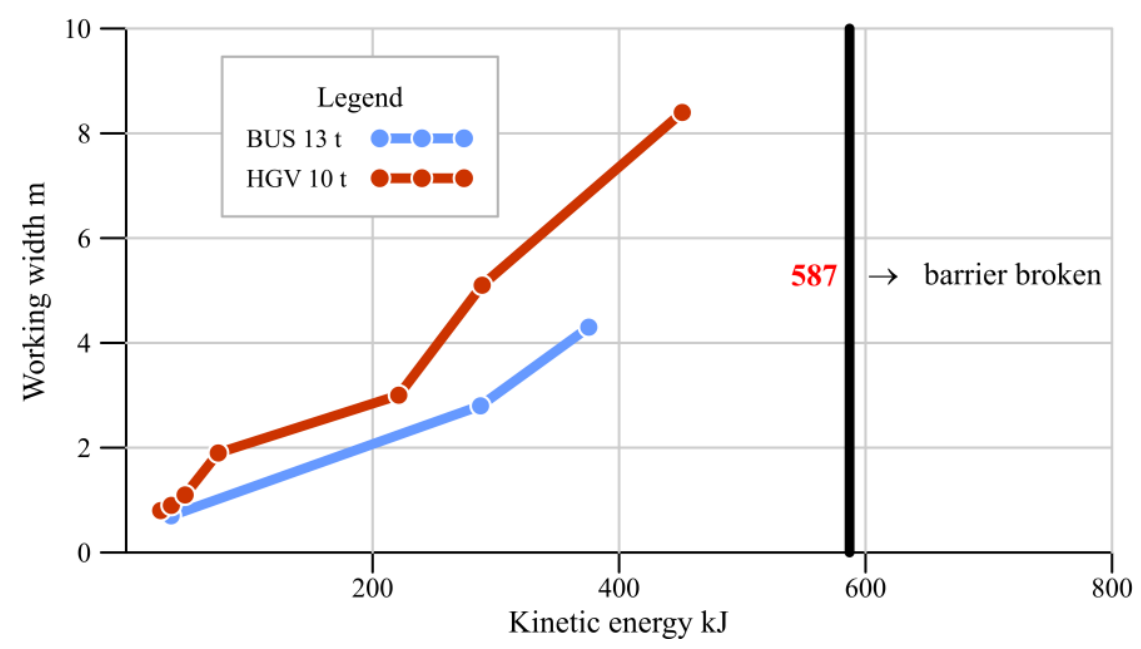

Fig. 11. Working width as a function of the initial kinetic energy for different vehicles.

\section{Conclusions}

The series of numerical tests have been successfully performed using verified models of the concrete barrier and cars. The obtained numerical results are in good agreement with experimental data The criterion for failure assessment of the concrete barrier segments have been proposed and good visual correlation between numerical and experimental data has been observed. The extensive parametric study with use of five vehicle models and various initial conditions have been performed. The resulting database for temporary concrete road safety barrier under various types of initial impact conditions have been determined and this table can be used in later research or as a supplementary material for concrete barriers design.

This work was supported by the National Centre for Research and Development (NCBiR) and General Directorate for National Roads and Motorways (GDDKiA), Poland. The research project name was "Life Cost analysis of Road Safety Elements" (contract number DZP/RID-I64/12/NCBR/2016 and DZP/RID-I-67/13/NCBR/2016). LS-DYNA calculations were carried out at the Academic Computer Centre in Gdańsk, Gdańsk University of Technology.

\section{References}

1. European Standard EN 1317-1-5 (2010)

2. British Standard PD CEN/TR 16303-1-5 (2012)

3. J.O. Hallquist, LS-DYNA Theory Manual (Livermore Software Technology Corporation, 2006)

4. LS-DYNA Keyword User's Manual (Livermore Software Technology Corporation, 2015)

5. K. Jamroz, S. Burzyński, W. Witkowski, K. Wilde, Numerical methods for the assessment of bridge safety barriers, in: M. Kleiber, T. Burczyński, K. Wilde, J. Gorski, K. Winkelmann, Ł. Smakosz (Eds.), Adv. Mech. Theor. Comput. Interdiscip. Issues, 1st ed., pp. 231-234 (CRC Press, 2016)

6. W. Borkowski, Z. Hryciów, P. Rybak, J. Wysocki, Numerical simulation of the standard TB11 and TB32 tests for a concrete safety barrier, J. KONES Powertrain 
Transp. 17 pp. 63-71 (2010)

7. M. Borovinšek, M. Vesenjak, M. Ulbin, Z. Ren, Simulation of crash tests for high containment levels of road safety barriers, Eng. Fail. Anal. 14 pp. 1711-1718 (2007). doi:10.1016/J.ENGFAILANAL.2006.11.068

8. K. Wilde, K. Jamroz, D. Bruski, S. Burzyński, J. Chróścielewski, W. Witkowski, Numerical simulations of bus crash-test with barrier and truss supporting structure (in Polish), J. Civ. Eng. Environ. Archit. 63 pp. 455-467 (2016)

9. M. Klasztorny, D.B. Nycz, P. Szurgott, Modelling and simulation of crash tests of N2-W4-A category safety road barrier in horizontal concave arc, Int. J. Crashworthiness. 21 pp. 644-659 (2016). doi:10.1080/13588265.2016.1212962

10. K. Wilde, D. Bruski, S. Burzyński, J. Chróścielewski, W. Witkowski, Numerical crash analysis of the cable barrier, in: J. Awrejcewicz, M. Kaźmierczak, J. Mrozowski, P. Olejnik (Eds.), DSTA-2017 Conf. Books, pp. 555-566 (Department of Automation, Biomechanics and Mechatronics, 2017)

11. M. Klasztorny, K. Zielonka, D.B. Nycz, P. Posuniak, R.K. Romanowski, Experimental validation of simulated TB32 crash tests for SP-05/2 barrier on horizontal concave arc without and with composite overlay, Arch. Civ. Mech. Eng. 18 pp. 339-355 (2018). doi:10.1016/J.ACME.2017.07.007

12. K. Wilde, K. Jamroz, D. Bruski, M. Budzyński, S. Burzyński, J. Chroscielewski, W. Witkowski, Curb-to-Barrier Face Distance Variation an a TB51 Bridge Barrier Crash Test Simulation, Arch. Civ. Eng. 63 pp. 187-199 (2017). doi:https://doi.org/10.1515/ace-2017-0024

13. P. Baranowski, J. Malachowski, J. Janiszewski, J. Wekezer, Detailed tyre FE modelling with multistage validation for dynamic analysis, Mater. Des. 96 pp. 68 79 (2016). doi:10.1016/J.MATDES.2016.02.029

14. P. Baranowski, J. Malachowski, L. Mazurkiewicz, Numerical and experimental testing of vehicle tyre under impulse loading conditions, Int. J. Mech. Sci. 106 pp. 346-356 (2016). doi:10.1016/J.IJMECSCI.2015.12.028

15. P. Baranowski, J. Janiszewski, J. Małachowski, Tire rubber testing procedure over a wide range of strain rates, J. Theor. Appl. Mech. 55 pp. 727-739 (2017). doi:10.15632/jtam-pl.55.2.727

16. P. Baranowski, J. Malachowski, Numerical study of selected military vehicle chassis subjected to blast loading in terms of tire strength improving, Bull. Polish Acad. Sci. Tech. Sci. 63 pp. 867-878 (2015). doi:10.1515/bpasts-2015-0099

17. J.C. Kennedy, C.A. Plaxico, C.R. Miele, Development of an NCHRP Report 350 TL-3 New Jersey Shape 50-Inch Portable Concrete Barrier (Ohio Department of Transportation, 2006)

18. R.W. Bielenberg, R.K. Faller, T.E. Quinn, D.L. Sicking, Development of a retrofit, low-deflection, temporary concrete barrier system. Research Project Number TPF5(193) Suppl. \#15 NDOR Sponsoring Agency Code RPFP-WISC-4 (Midwest Roadside Safety Facility, 2014)

19. T. Belytschko, W. Liu, B. Moran, Nonlinear finite elements for continua and structures (Wiley, 2000)

20. Y. Wu, J.E. Crawford, J.M. Magallanes, Performance of LS-DYNA Concrete Constitutive Models, in: 12th Int. LS-DYNA Users Conf., (2012)

21. H. Jiang, J. Zhao, Calibration of the continuous surface cap model for concrete, Finite Elem. Anal. Des. 97 pp. 1-19 (2015). doi:10.1016/J.FINEL.2014.12.002 
22. Y.D. Murray, Users Manual for LS-DYNA Concrete Material Model 159. Report no. FHWA-HRT-05-062 (Federal Highway Administration, 2007)

23. Y.D. Murray, A. Abu-Odeh, R. Bligh, Evaluation of LS-DYNA Concrete Material Model 159. Report no. FHWA-HRT-05-063 (Federal Highway Administration, 2007)

24. Y.D. Murray, B.A. Lewis, Numerical Simulation of Damage in Concrete. (APTEK INC COLORADO SPRINGS CO, 1995)

25. L.E. Schwer, Y.D. Murray, A three-invariant smooth cap model with mixed hardening, Int. J. Numer. Anal. Methods Geomech. 18 pp. 657-688 (1994). doi:10.1002/nag.1610181002

26. W.L. Oberkampf, M.F. Barone, Measures of agreement between computation and experiment: Validation metrics, J. Comput. Phys. 217 pp. 5-36 (2006). doi:10.1016/J.JCP.2006.03.037

27. M. Mongiardini, M.H. Ray, M. Anghileri, Development of a Software for the Comparison of Curves During the Verification and Validation of Numerical Models, in: 7th Eur. LS-DYNA Conf., (2009)

28. M.H.. Ray, M.. Mongiardini, C.A.. Plaxio, M. Anghileri, NCHRP Web-Only Document 179: Procedures for Verification and Validation of Computer Simulations Used for Roadside Safety Applications (Transportation Research Board, 2010)

29. ROBUST

PROJECT: https://www.vegvesen.no/s/robust/Computational_mechanics/Vehicle models/, (2018)

30. K. Wilde, D. Bruski, S. Burzyński, J. Chróścielewski, Ł. Pachocki, W. Witkowski, On the validation of the LS-DYNA Geo Metro numerical model (to be published), in: 64 Sci. Conf. Krynica Zdrój, (2018) 